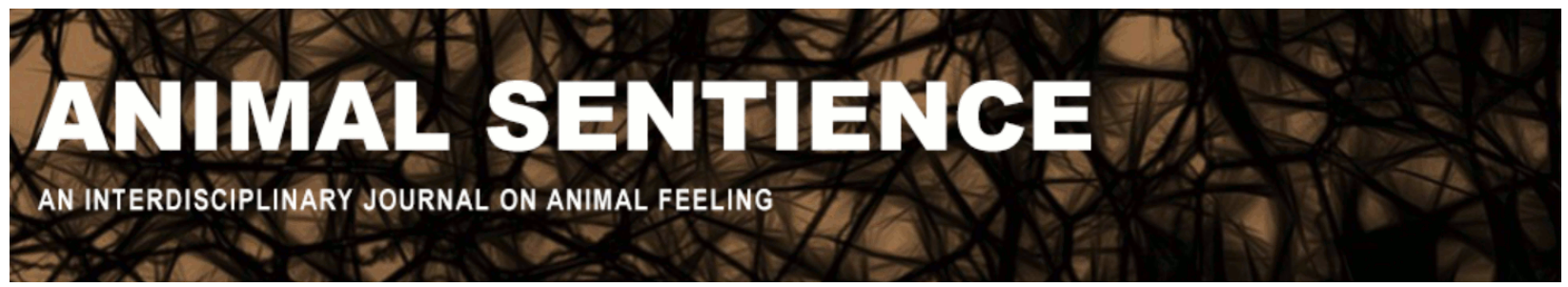

Key, Brian and Brown, Deborah (2020) Minds, morality and midgies. Animal Sentience 29(24)

DOI: $10.51291 / 2377-7478.1619$

Date of submission: $2020-07-12$

Date of acceptance: 2020-07-16 (c) 


\title{
Minds, morality and midgies
}

Commentary on Mikhalevich \& Powell on Invertebrate Minds

\section{Brian Key \\ School of Biomedical Sciences, University of Queensland \\ Deborah Brown \\ School of Historical and Philosophical Inquiry, University of Queensland}

\begin{abstract}
Mikhalevich \& Powell argue that the exclusion of the vast majority of arthropods from moral standing is unwarranted, particularly given the purported evidence for cognition and sentience in these organisms. The implied association between consciousness and moral standing is questionable and their assumption that rich forms of cognition and flexible behavior are dependent on phenomenal consciousness needs to be reconsidered in light of current neuroscientific evidence. We conclude by proposing a neural algorithmic approach for deciphering whether organisms are capable of subjective experience.
\end{abstract}

Brian Key is Professor and head of the Neurophilosophy Lab at the University of Queensland. He has extensive experience in comparative neurology using model organisms (fish, frogs and rodents). He is currently co-funded with Deborah Brown by an Australian Research Council large grant to investigate "Towards Closure on the Animal Pain Debate" Website

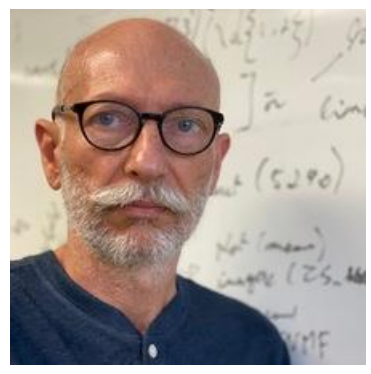

Deborah Brown is Professor of Philosophy and Director of the UQ Critical Thinking Project. She has published widely in the history of philosophy and philosophy of mind and is currently working with Brian Key on an Australian Research Council project, Towards Closure on the Animal Pain Debate. Website

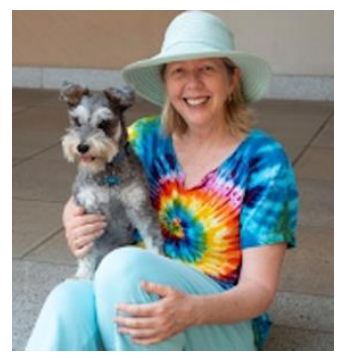

Issues concerning who or what has 'moral standing' are related to questions of who or what is a person, not (directly at least) to whether an entity has the capacity for consciousness. As pointed out by Locke (1689/1694), 'person' is a 'forensick' (i.e. legal) notion, which is why bridges, churches, corporations, and non-rational animals, including insects, have at one time or another been afforded the status of persons historically. Animal welfare laws, by contrast, are targeted at things which have a 'well-being', and seek inter alia to protect organisms from unjustifiable, unnecessary or unreasonable pain. When thinking about our moral obligations to nonhuman animals, it is crucial to be clear on what sort of harm is at issue and to recognise that although they are obviously connected, the terms 'harm' and 'pain' are by no means coextensive. 
Contrary to what Mikhalevich \& Powell (2020) (M\&P) suggest, a species that lacks the capacity for consciousness need not lack intrinsic (non-instrumental) value any more than churches or corporations that are recognised as legal persons do. We should not let our desire to see protections extended to species phylogenetically distant from humans shape the way we interpret neuroscientific findings. Although we see M\&P's target article as providing an excellent starting point for robust discussion about the capabilities of insects and their value, M\&P's conclusions exceed the neuroscientific evidence on which they rely.

M\&P build a prima facie case for the moral standing of arthropods on the grounds that they have a "psychological welfare of their own". Arthropods have a centralised brain and they exhibit "rich forms of cognition" and flexible, complex behaviours. Confusingly, M\&P state at one point that neither cognition nor complex behaviours are "necessary conditions for moral standing, since creatures may be sentient even if they lack, say, numerosity, transitive inference, or problem solving". We agree, having raised similar concerns previously (Key, 2015, 2016; Key and Brown, 2018). Although there are different working definitions of 'cognition', the consensus is that it involves the planning and execution of complex behaviours to solve a problem or to achieve a goal. In humans, cognition involves both conscious higher-order functions (Miller and Wallis, 2009) and non-conscious information processing (LeDoux and Brown, 2017). The latter is necessary but not sufficient for consciousness. Failure to recognise this distinction leads M\&P to conclude falsely that all complex behaviours are under volitional control-that arthropod behaviour is "probably underwritten" by sentience or subjective experience (e.g. pleasure and pain), simply because it is mediated by information processing.

Unfortunately, no evidence that sentience is necessary for cognition or the "flexible learning abilities" of arthropods is provided. M\&P assume that all complex behaviours depend on the ability of organisms to "attach feelings to objects and actions". There is a circular quality to their reasoning here. Having bestowed sentient qualities on flexible learning behaviours, they infer from observing those behaviours that arthropods are sentient-e.g., "bumblebees tend to interpret ambiguous stimuli more optimistically after exposure to a pleasant stimulus, just as humans do when they are happy or calm". The intentionalist language of 'interpretation' and 'pleasantness' of the stimuli and the analogy with human happiness and tranquility are questionbegging; the reference to 'ambiguity' implies a choice between two representations of the stimulus; 'optimism' that the choice bears some affect. Spurious assumptions! Many things that opt for one action over another (including telephone cables and microcircuits) and that increase optimality are not thereby experiencing pleasure or optimism.

We admit to being sometimes confused by M\&P's strategy of argument. They often express caution against leaping to conclusions on the basis of insufficient evidence but then proceed to do just that. Pointing the finger at "scientific uncertainty" about vertebrate consciousness does not help strengthen their case. They are certainly right in arguing that the same "evidentiary standard" should apply to vertebrates and invertebrates; but if they are also right about the lack of evidence for vertebrate consciousness, rationality would dictate withholding assent to claims about consciousness in both cases. The two cases are not symmetrical, however, because we have good reason, on the basis of structural homologies, to conclude about many vertebrate species that they are conscious. M\&P's retort that arguments from homology are baseless because all homology claims about brain regions are ultimately 
based on behaviour-and so it is to similarities of behaviour not their structural bases that we should look to make judgements of sentience-is wildly out of step with fundamental principles of comparative neurobiology.

We agree that comparing homologies of gross brain regions across phylogenetically distant species (e.g. between fish or insects and humans) is of limited value. For comparative purposes, a different level of abstraction and approach is required. By identifying the algorithm (sequence of neural functions) necessary for subjective experience and then seeking to define the specific neural structures (e.g., neural architectures and neural circuitry) that could possibly execute that algorithm among different species, we can begin to make real progress. Experimental work on the visual system has already revealed that common algorithms are used in both insects and mammals (Borst and Helmstaedter, 2015). The principle that structure determines function is fundamental in biology. When examined at the appropriate level of analysis it can be a powerful tool for addressing the possibility of subjective experience in specific organisms (Key and Brown, 2018).

\section{References}

Borst, A. \& Helmstaedter, M. (2015) Common circuit design in fly and mammalian motion vision. Nature neuroscience, 18(8):1067-1076.

Key, B. (2015) Fish do not feel pain and its implications for understanding phenomenal consciousness. Biology \& Philosophy 30(2):149-165.

Key, B. (2016) Why fish do not feel pain. Animal Sentience 3(1).

Key, B. \& Brown, D. (2018) Designing brains for pain: human to mollusc. Frontiers in physiology, 9:1027.

LeDoux, J.E. \& Brown, R. (2017) A higher-order theory of emotional consciousness. Proceedings of the National Academy of Sciences, 114(10):E2016-2025.

Locke, John. (1689/1694) An Essay Concerning Human Understanding, Peter H. Nidditch (ed.), Oxford: Oxford University Press, 1975: 2.27.26.

Mikhalevich, Irina \& Powell, Russell (2020) Minds without spines: Evolutionarily inclusive animal ethics. Animal Sentience 29(1)

Miller, E.K. \& Wallis, J.D. (2009) Executive function and higher-order cognition: definition and neural substrates. Encyclopedia of neuroscience, 4:99-104. 